\title{
IMPLEMENTING ADVANCE CARE PLANNING IN 'THE AGE OF DEFERRED DEATH'- THE HONG KONG EXPERIENCE OVER 4 YEARS
}

\author{
J. WOO \\ Department of Medicine and Therapeutics, Faculty of Medicine, The Chinese University of Hong Kong, Hong Kong. Corresponding author: Prof Jean Woo, Department of Medicine \& \\ Therapeutics, Prince of Wales Hospital, Shatin, N.T. Hong Kong, Tel: 852-3505-3493, Fax: 852-3505-3852, Email: jeanwoowong@cuhk.edu.hk
}

\begin{abstract}
Objectives: To plan, implement and evaluate a series of initiatives to improve patient centred quality of end of life care through raising public awareness, promoting the concept that all health and social care professionals should be engaged in this practice, and carrying out pilot of community care models. Design: Pilot studies of community models of care, training programs for health and social care professionals, public education programmes. Setting: Selected hospitals, residential care homes for the elderly, and community centres in Hong Kong. Participants: Patients and their families at the end of life stage. Measurements: Combination of quantitative and qualitative studies according to different components of the initiative. Results: Effective training for professional staff occurred using training videos, role play, rather than lectures, and when concepts are integrated into daily practice and quality assurance programmes. Members of the public welcomed end of life care discussions and the implementation of advance care planning. The pilot community care program was found to reduce anxiety, depression, physical symptoms, improve communication within the family as well as promoting a feeling of peace among recipients of the service. It also reduced care giver strain and anxiety, as well as hospital visits and duration of stay. Similar findings were also observed among recipients of care in the residential care setting. Conclusion: A sustainable model would require uptake by policy makers and chief executives of Social Welfare and Health Bureaus, supported by amendments of relevant legal ordinances, which is in progress after public consultation.
\end{abstract}

Key words: End of life care, older adults, frailty, advance care plan.

\section{World-wide discourse}

World-wide populations are aging, accompanied by increase in absolute numbers of people with multiple chronic diseases and frailty. This situation has been aptly described as 'deferred death'(1). In the same way that patients with cancer receive palliative care, patients with chronic diseases of varying trajectories also deserve palliative care. Unfortunately palliative care services and training have evolved around cancer services, and are relatively underdeveloped (both training and service models) even though the percentage of people dying from noncancer causes such as heart failure, neurodegenerative diseases and dementia exceed those dying from cancer.

The importance of initiating a conversation about patients' wishes towards end of life care has been eloquently described by Gawande (2) and incorporated into the framework for quality of care at the end of life $(3,4)$. There has been a gradual paradigm shift to initiate conversations early as part of advance care planning (ACP) rather than at the terminal stage; to apply to chronic diseases other than cancer; to develop community models using a public health perspective instead of a predominantly medical model centred in hospitals, and to involved multidisciplinary teams (5-7). Such initiatives are accompanied by public education and promotion of dialogue around end of life care choices and services.

Currently there is much debate and controversies around these areas. The use of the term advance care planning has been questioned, with a suggestion to replace 'advance' with 'adaptive' to take into account unexpected diagnoses with Received December 17, 2020 rapid deterioration (8). A series of studies in palliative care in the UK questioned the perceived conventional wisdom around best medical practices in hospital and general practice settings (9-11). The COVID 19 pandemic highlights the urgent need for such service developments. Thus the Institute of National Academies stated that "provision of palliative care in the context of a disaster with scarce resources can be considered a moral imperative of a humane society (12), and the COVID 19 pandemic may be viewed in the light of a 'disaster'. Yet there is a gap from dialogue and ideal practices, to integration into current services. Achieving this goal require changing mind sets of service providers as well as members of the public, policy changes, uptake by hospital and community service providers, as well as ensuring financial sustainability. In spite of these challenges, there is no doubt that this area has received much attention in both the public domain (13) as well as academia $(14,15)$.

This topic is particularly relevant for Hong Kong since evidence suggests that increase in life expectancy has been accompanied by increasing trends of frailty and disability $(16,17)$, with increasing use of hospital services in the last years of life (18). This article describes a possible strategy and ongoing efforts in achieving improvements in the quality of care at the end of life from the patient's perspective, which of necessity involves change in mind set at societal, professional, organizational, and policy levels accompanied by changes in legal framework. 


\section{THE JOURNAL OF NUTRITION, HEALTH \& AGING}

\section{The Hong Kong experience in transition: obstacles, strategies, sustainability}

Palliative care was established as a specialty in the Hong Kong College of Physicians since 1997, with a well defined training pathway. However for many years the service was regarded as part of cancer management. With population ageing, the need for applying palliative principles and service to non cancer patients with various chronic conditions and frailty steadily grew, from geriatric services to hospital-supported residential care homes for the elderly, within the framework of quality improvement initiatives of improving the quality of care at the end of life (19). Experience gathered during this stage showed that there is a need for raising capacity to provide quality end of life care among healthcare professionals that is not confined to the palliative medicine specialist, as well as extensive public education to raise health literacy in this area. At this time there was growing media interest and reports in end of life care emphasizing the palliative care approach, and the Hong Kong government commissioned the Chinese University of Hong Kong to carry out a review on health services for the elderly including end of life care. The findings provided an overview of the areas of need to guide quality improvement (20). To summarize, services for end-stage noncancer patients are poorly developed compared with palliative services for cancer patients, even though such patients have a high prevalence of symptoms similar to cancer patients. Indeed adequate staff training and experience have been identified as one of the key features of quality end of life care (EOLC), and at the same time the predominant curative focus in medical care forms a barrier (15). A case note audit of 61 patients with a mean age of 84 years characterized by multi morbidity and disabilities ( $54 \%$ being residents of long term care homes) who died in an acute general hospital during the last 180 days, showed that EOLC conversations occurred in only $21 \%$, with no patients having an advance care plan or advance directives, even though $79 \%$ had a 'do not resuscitate' order (21). There are few measures of competence in caring for patients who are at the end of life.

In 2016 the largest philanthropic foundation in Hong Kong initiated a territory wide project with partners from academia, the Hospital authority and non-government organizations running residential care homes for the elderly, to raise capacity in end of life care among health and social care professionals in hospitals and residential care homes, to pilot a community care model of end of life care, as well as public education [http://foss.hku.hk/jcecc/en/]. The Jockey Club End-of-Life Community Care (JCECC) project that involves multiple partners in community, residential care and hospital settings reflects the recent promulgation of compassionate communities as part of the public health approach to end of life care (22). Central to the ever widening circles of care is the person with illness, the first contact being hospital and staff managing the illness. How this is managed would affect the subsequent widening circles of care, and therefore quality improvement is crucial for whether subsequent support networks are able to provide support. Currently a huge quality care gap exists in hospitals with respect to the palliative care needs of frail older patients. For example it has been estimated that the principle drivers of need for palliative care will probably be dementia rather than cancer in the UK (23). In Hong Kong the average life expectancy for men and women is between 80-90 years. Approximately $70 \%$ of patients in general medical wards are 80 years and above, with $50 \%$ classified as frail, and between 30-50\% residing in RCHEs. Approximately one third have dementia. It is known that use of hospital services is concentrated in the last year(s) of life (18). In this scenario, it may be expected that a substantial number will be at the last stage in life and that initiation of EOLC conversations and advance care plan (ACP) would be appropriate. Such conversations allow discussion with family members regarding the wish of the patient with regard to intensity of life sustaining treatments, time for preparation with a focus on what matters most to the patient at the end of life.

In the document published in the UK outlining a national framework for local action 2015-2020, the uniqueness of each person should be recognized by honest and timely conversations with consideration of patients' preferences and provision of information for patients and their families to make informed choices (24). Better communication skills should be a key component of doctors' and medical students' training (4). Such training programs have also been advocated in the USA Institute of Medicine Report Dying in America (3), and an example of such a program is the Serious Illness Care Program teaching early initiation of serious illness conversations and organization of communication skills workshop (25).

In acute hospital settings, end of life care 'should be everybody's business' (26), and education and training in EOLC would improve the quality of care and improve the experience of patients and their families. Due to the increasing number of frail older people in hospitals, EOLC should not be seen as the sole responsibility of specialists in Palliative Medicine, but viewed as the responsibility of all professionals. Several challenges to EOLC education need to be addressed in improving staff competency that effectively equates with change in mindset and behavior; but most importantly it should be guided by patients' and families' viewpoints. Organizational support, continuous training on the job, role modelling, role play, audit, evaluation of effectiveness are all important ingredients that accompany a knowledge-based core curriculum. A key area of competence to address is how to engage in conversations about EOLC, a skill that many doctors and medical students lack (27).

The JCECC project was guided by these principles [Fig.1]. It may be viewed as action research, as evaluation was carried out with each initiative, and subsequent strategies may be modified to take into account response from professionals and the public, as well as to changing organizational policies. This 
article attempts to chronicle this initiative to improving the quality of care and address unmet needs of the aging population in Hong Kong, by documenting the rationale for plan of action, to describe the various stages over a period of four years, and to critically assess what has been achieved, what strategies are successful, and what remains to be done.

\section{Figure 1}

Components of the JCECC project

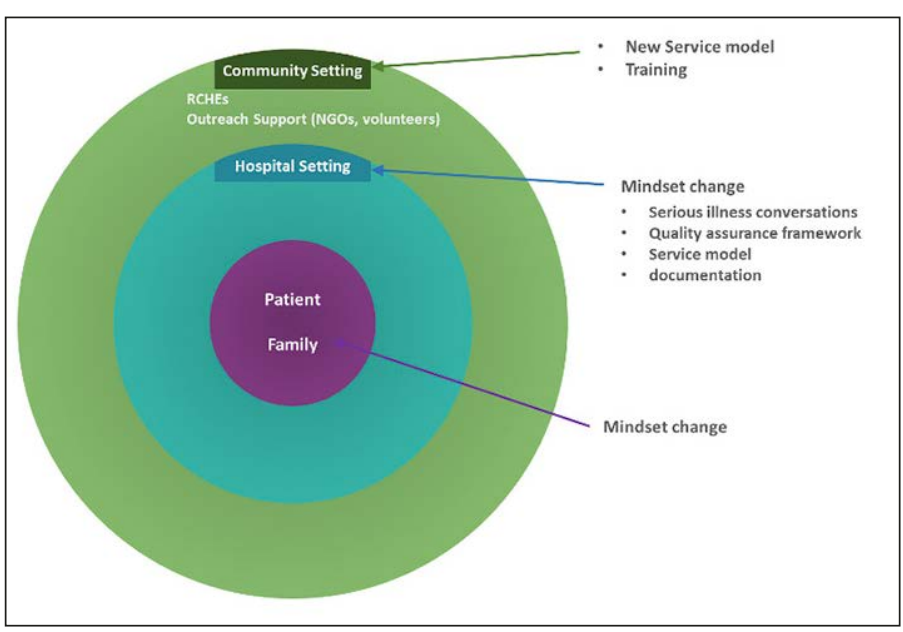

Raising capacity in hospitals

In the initial phase, a series of topics were planned to be covered in workshops or lectures/seminars, in hospitals in one geographical region (NTE) as a pilot to examine feasibility, uptake and effectiveness. The objective was to deal with avoidance and lack of knowledge among hospital staff in how to talk to patients and relatives, resulting in the default option of drugs, machines and artificial hydration and nutrition, lack of knowledge about advance directives, enduring power of attorneys, and approach for those who are mentally incapacitated. The education program included the following: how to identify patients at the end of life; how to promote advance care plans through initiating exploratory conversations with patients and family regarding their wishes and preferences. The program was planned as a partnership with the Hospital Authority (HA) in strengthening the quality EOLC model and practices in hospitals and achieve sustainability through documentation of such practices through the audit and accreditation process.

At the beginning of the project, we sought to obtain an indication of the degree in competence in death works using a locally derived and validated death competence scale (28). 855 health and social care workers in the eight institutions in the pilot region (NTE) attending initial sessions of talks at various hospitals were invited to complete this death competence survey between January and October 2016. The findings show that competence varied between different institutions, reflecting differences in organizational goals and staff training, and increased with age of staff and personal bereavement experience. Unexpectedly there was no difference in competence among nursing staff compared with personal care assistants. The number of doctors surveyed was too few for comparison. The survey identified factors contributing to competence: personal resources, existential challenges and coping, emotional challenges and coping, and need for improvement in self-competence. The survey showed that there is room for improvement in self-competence in death work among health and social care workers, especially among the younger age group, nurses, and those working in acute hospitals (29). There were also barriers to advance care planning from the patients' and families point of view (30), and implementation of service changes $(31,32)$. These studies showed that improvement in end of life care is needed in promotion and training end of life care conversations for health and social care professionals as well as patients and families, and fit for purpose services in both the institutional and community settings. The perception that such conversations belong to the domain of palliative care specialist is widespread. Furthermore improvement would involve a paradigm shift relating to society as a whole, with a government led policy framework and the development of a public health approach with community services support.

Details of the programmes carried out to raise capacity include running sessions for hospital staff (doctors, nurses, social workers etc), consisting of a series of talks, workshops, case discussions, involving both large (40-200) and small (1030) groups. Doctors, nurses, or social workers conducted these sessions. Real cases were discussed; either current ongoing problems or past cases, especially those that resulted in conflict either between family members, between patient and family, or between hospital staff and family. Simulation workshops in communication skills were also held. Contents of the EOL capacity building programmes vary according to the target audience, and were delivered via talks using case presentations; group discussion of individual experiences; and role play especially for training of communication skills; and through artistic media e.g. art, drama. At each of these sessions, one observer recorded questions and discussions raised.

Preliminary observations showed that nurses in general were more receptive and keen to learn about end of life conversations; yet some express moral distress because the doctors behave in a different way and unless the management plan is agreed, the doctors' decision always takes precedence, and so they cannot practise what they learnt. Among doctors, there was wide variation in knowledge regarding the management of symptoms, prescribing of drugs, what is end of life care and the diagnosis of the end of life phase, how to initiate end of life conversations, advance directives (Ads) and ACPs. Many doctors avoid/refuse signing AD as they were afraid of subsequent litigation. Other reasons cited include: lack of time, uncertainty regarding when such conversations should be initiated, and not being a palliative care specialist. 


\section{THE JOURNAL OF NUTRITION, HEALTH \& AGING}

These observations guided formulation of subsequent action plans, with the objective of engaging all doctors in end-of-life care instead of delegating it to palliative care specialists; achieving mindset change for all doctors such that end-of-life care principles should be incorporated into regular clinical meetings with case discussions, videos of case histories and critique of management. Training in endof-life care conversation, AD and ACP, with documentation was implemented to achieve these objectives, using a series of videos of doctors conducting serious illness conversations according to steps (33) for various chronic diseases including dementia as well as cancer were made, and used for doctors training sessions (34).

\section{Raising capacity in residential care homes for the elderly (RCHE)}

Education sessions for RCHE staff on ACP conversations, $\mathrm{ACP}$ and $\mathrm{AD}$, were carried out at the same time, where the: format and content were adapted to fit the RCHE setting. Medical care for RCHE residents was provided by HA Geriatric Outreach teams, which had already formed a pathway of care such that whenever possible, EOL care may be provided at the RCHE, avoiding attendances at Emergency Departments or hospital admissions. For a select group of RCHE, funding was made available for participatory training where a multidisciplinary outreach team provided on site advice and service for end of life care. This intervention resulted in reduced physical and psychological symptoms, improved communication with family members especially in terms of preferences to end of life care decisions. Utilization of hospital services was also reduced.

\section{Community model of end of life care}

The predominantly private primary care system effectively contributed to unmet palliative care needs in the community. A community palliative care pilot model was developed and evaluated by the Department of Social Work in the University of Hong Kong, and implemented by non-government organizations and volunteers from NGO members. Patients with diagnoses of cancer or end stage chronic diseases such as chronic pulmonary disease discharged home from hospital received support from NGOs centres covering physical and psychosocial support, solving practical problems, dealing with caregiver strain, and promoting psychological support from family and friends. Training of NGO staff and volunteers was provided by staff from the Department of Social Work to NGO staff as well as volunteers. This intervention was found to reduce anxiety, depression, physical symptoms, improve communication within the family as well as promoting a feeling of peace among recipients of the service. It also reduced care giver strain and anxiety, as well as hospital visits and duration of stay. Similar findings were also observed among recipients of care in the residential care setting.

\section{Public education}

To address the lack of knowledge on the part of patients and family regarding EOL choices, the balance between prolonging death with suffering (i.e. bad quality of dying) versus expectation of recovery and cure, in the hospital setting, which not infrequently contribute to conflict between hospital staff and family members, we simultaneously ran public education programs on curative versus palliative treatment, and how to initiate serious illness conversations with doctors. We made videos to portray realistically what life prolonging treatment involves- use of ventilators, artificial nutrition and hydration, cardiopulmonary resuscitation, compared with the comfort care option. The sessions encouraged reflections on end of life choices and how these can be discussed with family members, communicated to healthcare professionals, and documented. The audience include older people from the community, those linked with the RCHE settings, as well as patients and their families who are frequently admitted to hospitals. Group meetings of up to ten people consisting of patients as well as family members were particularly effective in addressing any misconceptions about treatments, and the option of choice of treatment that is centered on the wishes of the patient. Practical details regarding documentation of patient wishes were introduced. Information dissemination strategies include short video clips via you tube, booklets using cartoons, working groups centred around related themes with activities such as writing ACP for participants themselves, exhibitions in public places such as libraries and mass transit railway stations, drawing competitions on end of life topics for different groups from students, health and social care professionals, and older adults (35). Practical points such as enduing power of attorney, financial arrangements, nominating a family decision maker, making advance directives and wills etc were included. These session also aim to prepare patients and families psychologically for the end of life experience. These topics were also extensively covered in the media, by well-known prominent figures in the public and entertainment arena.

It is interesting that members of the public appear to take up the idea of AD and ACP much more readily than healthcare professionals. Doctors seem reluctant to engage in this topic and avoid agreeing to sign ADs even when asked by patients. Yet patients state they want to decide early when they are of sound mind and not under physical or psychological distress, to be able to talk to their relatives about it. The movement to further empower the public to facilitate initiation of the conversation with medical and healthcare professionals about the prognosis, ACP and AD. would be an important driver towards patient centred end of life care. 


\section{Insight and conclusions}

What has been achieved as a result of the current project is that an awareness of the possibility of expressing choice of end of life care through early conversations and documentation of wishes has been raised among the public, hospital and community care settings, and gathered overall support among all stakeholders. A pilot model of community end of life care has also been implemented and shown to have met patient related goals as well as reduced the use of hospital services. Training using traditional methods of talks have not been shown to be as effective, without a strategy for increasing motivation. Methods used need to incorporate sharing of actual experiences through videos or group discussions, as well as embedded in individual professional assessment such as higher professional examinations, or organizational quality assurance programmes. Public engagement was effective through multiple media channels and interactive activities. More work needs to be done to narrow the gap between training and practice; to address organizational anxiety about litigation from families (frequently as a result of poor communication and family discord), and amendments of relevant government ordinance to facilitate the implementation of ACPs and ADs. Continuation of various activities of the JCECC project as well as passing of the amendments of government ordinances by the Legislature would go some way to achieving these goals. The use of technology may have a role in future to aid identification of those patients for whom initiating ACP discussions may be appropriate, by making use of big data that is routinely collected. For example in the UK the NHS hospital and General Practice databases are being used to develop a second version of the electronic frailty index (eFI) (36). In Hong Kong the use of the Harpe score (37) (developed using hospital data on frequency of past admissions and diagnoses of certain chronic diseases, which is incorporated into the electronic patient records), maybe be used to alert doctors as an indicator of initiating end of life care conversations, since patients with a score of $>=4$ have a mortality rate of $40 \%$ after six months [Ing $\mathrm{C}$, unpublished results].

It can be seen that changing current practices in end of life care requires a paradigm shift, carried out as an iterative process, adopting an action research approach. Central to this paradigm shift is to place the needs and wishes of patients (and their families if relevant) as the central driver, in terms of meeting their needs [see Fig 2]. Strategies to achieve changes need to consider service settings, to involve both hospital as well as community organisations, health as well as social service providers. A collaborative co-creation process with service providers and recipients, building on existing service structures is needed. Cost effectiveness studies, legislative and/ or policy changes, together with changes in service providers' framework would need to take place. Within a particular setting, such as hospitals, it may be easier to implement these changes building on existing quality assurance framework to ensure sustainability. Finally initiatives for improvement would need to be accompanied by educational efforts simultaneously among the public as well as all service providers, to facilitate communication.

Figure 2

Structural components for meeting wishes of patients

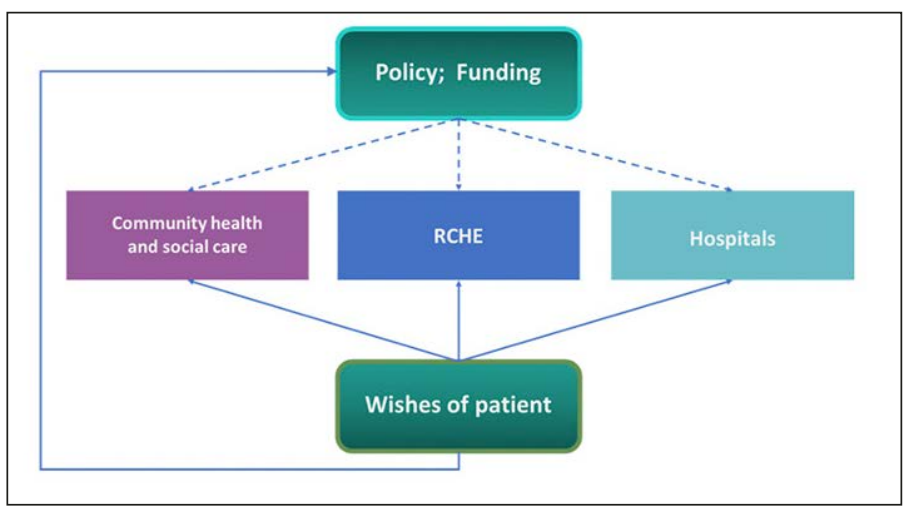

At this stage of development it is uncertain whether all components described in Fig 2 could be achieved, since additional funding would be needed to develop community services, while the service infrastructure for hospitals and residential care settings already exist: what is needed is change in practice. The absence of a publicly funded primary care service in Hong Kong would be a major barrier to implementing community end of life care for the majority of the population. In future models involving insurance or co-payments could be explored. Finally, this report show how philanthropic support could be a key driver to change, since these initiatives would not have taken place otherwise. Nevertheless in order to complete the quality improvement loop, a sustainable model would require uptake by policy makers and chief executives of Social Welfare and Health Bureaus, supported by amendments of relevant legal ordinances, which is in progress after public consultation.

Conflicts of interest: The author declares no conflicts of interest.

Ethical standards: The surveys were approved by the Survey and Behavioural Ethics Committee of the Chinese University of Hong Kong and was performed in accordance with relevant guidelines and regulations.

Acknowledgement: This work is supported by the Hong Kong Jockey Club Charities Trust.

\section{References}

1. Mitchell G, Murray SA. Supportive and palliative care in the age of deferred death: primary care's central role. BMJ Support Palliat Care. Published Online First: 24 September 2020. doi: 10.1136/bmjspcare-2020-002616.

2. Gawande A. Being mortal: Medicine and what matters in the end. New York: Metropolitan Books/Henry Holt and Company; 2014.

3. Institute of Medicine of the National Academies. Dying in America: Improving Quality and Honoring Individual Preferences Near the End of Life. Washington, DC: The National Academies Press. https://doi.org/10.17226/18748; 2015.

4. British Medical Association. End-of-Life Care and Physician-assisted Dying. 2016. 


\section{THE JOURNAL OF NUTRITION, HEALTH \& AGING}

5. Callaway MV, Connor SR, Foley KM. World Health Organization Public Health Model: A Roadmap for Palliative Care Development. J Pain Symptom Manage. 2018;55(2S):S6-S13.

6. Murray SA, Firth A, Schneider N, Van den Eynden B, Gomez-Batiste X, Brogaard T, et al. Promoting palliative care in the community: production of the primary palliative care toolkit by the European Association of Palliative Care Taskforce in primary palliative care. Palliat Med. 2015;29(2):101-11.

7. Tziraki C, Grimes C, Ventura F, O'Caoimh R, Santana S, Zavagli V, et al. Rethinking palliative care in a public health context: addressing the needs of persons with noncommunicable chronic diseases. Prim Health Care Res Dev. 2020;21:e32.

8. Moody SY. "Advance” Care Planning Reenvisioned. J Am Geriatr Soc. 2020. https:// doi.org/10.1111/jgs.16903

9. Bowers B, Ryan R, Kuhn I, Barclay S. Anticipatory prescribing of injectable medications for adults at the end of life in the community: A systematic literature review and narrative synthesis. Palliat Med. 2019;33(2):160-77.

10. Hopkins SA, Lovick R, Polak L, Bowers B, Morgan T, Kelly MP, et al. Reassessing advance care planning in the light of covid-19. BMJ. 2020;369:m1927.

11. Antunes B, Bowers B, Winterburn I, Kelly MP, Brodrick R, Pollock K, et al. Anticipatory prescribing in community end-of-life care in the UK and Ireland during the COVID-19 pandemic: online survey. BMJ Support Palliat Care. 2020;10(3):343-9.

12. Institute of Medicine of the National Academies. Crisis Standards of Care: A Systems Framework for Catastrophic Disaster Response: Volume 1: Introduction and CSC Framework. Washington, DC: The National Academies Press. https://doi. org/10.17226/13351.; 2012.

13. The Economist Intelligence Unit. The 2015 Quality of Death Index Ranking palliative care across the world. www.eiuperspectives.economist.com/sites/default/ files/2015\%20EIU\%20Quality\%20of\%20Death\%20Index\%20Oct\%2029\%20FINAL. pdf.

14. Wolf SM, Berlinger N, Jennings B. Forty years of work on end-of-life care--from patients' rights to systemic reform. N Engl J Med. 2015;372(7):678-82.

15. Threapleton DE, Chung RY, Wong SYS, Wong ELY, Kiang N, Chau PYK, et al. Care Toward the End of Life in Older Populations and Its Implementation Facilitators and Barriers: A Scoping Review. J Am Med Dir Assoc. 2017;18(12):1000-9 e4.

16. Yu R, Wong M, Chang B, Lai X, Lum CM, Auyeung TW, et al. Trends in activities of daily living disability in a large sample of community-dwelling Chinese older adults in Hong Kong: an age-period-cohort analysis. BMJ Open. 2016;6(12):e013259.

17. Yu R, Wong M, Chong KC, Chang B, Lum CM, Auyeung TW, et al. Trajectories of frailty among Chinese older people in Hong Kong between 2001 and 2012: an ageperiod-cohort analysis. Age Ageing. 2018;47(2):254-61

18. Woo J, Goggins W, Zhang X, Griffiths S, Wong V. Aging and utilization of hospital services in Hong Kong: retrospective cohort study. Int J Public Health. 2010;55(3):201-7.

19. Woo J. Quality of Life and Quality of Dying: Attaining the Optimal Goal. Arch Palliat Care. 2017;2(1):1009.

20. Yeoh EK, Wong ELY, Chung CH, Chung RY, Wong SYS, Woo J, et al. Quality of Healthcare for the Ageing - Health System and Service Models to Better Cater for an Ageing Population. https://rfs2.fhb.gov.hk/app/fundedsearch/projectdetail xhtml?id=1866.

21. Au DWH, Lee JSW, Chan HY, Wong MW, Cheung NL, Ng K, et al. An exploratory investigation into advance care planning, end-of-life communication and decisionmaking in an acute hospital setting. JCECC Conference: Collaboration in Creating Compassionate Holistic End-of-Life Care for the Future; Hong Kong 2017.

22. Abel J. Compassionate communities and end-of-life care. Clin Med. 2018;18(1):6-8

23. Millington-Sanders C. Passing the baton of trust. Clin Med. 2018;18(1):9-10.
24. National Partnership for Palliative and End of Life Care E. Ambitions for palliative and end of life care: A national framework for local action 2015-2020. United Kingdom; 2015

25. Bernacki R, Paladino J, Lamas D, Hutchings M, Lakin J, Neville BA, et al. Delivering more, earlier, and better goals-of-care conversations to seriously ill oncology patients. J Clin Oncol. 2015;33:29_suppl, 39-39.

26. Cox S, Brighton LJ, Russell S. End-of-life education in the acute setting Future Healthcare Journal. 2018;5(1):21-4.

27. St John K. The Second Conversation Project: improving end-of-life conversations. 2018:13.

28. Chan WC, Tin AF, Wong KL. Coping With Existential and Emotional Challenges: Development and Validation of the Self-Competence in Death Work Scale. J Pain Symptom Manage. 2015;50(1):99-107

29. Cheung JTK, Au DWH, Chan WCH, Chan JHY, Ng K, Woo J. Self-competence in death work among health and social care workers: a region-wide survey in Hong Kong. Bmc Palliat Care. 2018;17:65.

30. Cheung JTK, Au D, Ip AHF, Chan J, Ng K, Cheung L, et al. Barriers to advance care planning: a qualitative study of seriously ill Chinese patients and their families. Bmc Palliat Care. 2020;19(1):80

31. Wong ELY, Kiang N, Chung RYN, Lau J, Chau PYK, Wong SYS, et al. Quality of Palliative and End-Of-Life Care in Hong Kong: Perspectives of Healthcare Providers Int J Environ Res Public Health. 2020;17:5130.

32. Chan HYL, Lee DTF, Woo J. Diagnosing Gaps in the Development of Palliative and End-of-Life Care: A Qualitative Exploratory Study. Int J Environ Res Public Health. 2020;17(1):151.

33. Ariadne Labs. Serious Illness Care Program: Reference Guide for Interprofessional Clinicians. Retrieved from http://www.bcrenal.ca/resource-gallery/Documents/ ClinicianinterprofessionalReferenceGuide_V4_2018_01_19.pdf. 2016.

34. URLs for the videos: Goals of Care Options for Patients with Advanced COPD - for healthcare professionals: https://youtu.be/o95hlGTcVHo; Understanding Care Decisions in Advanced Heart Failure - for healthcare professionals: https://youtu.be/Mf7EzSsIn1E; End-of-Life Care: Discussion of Advance Care Planning - for healthcare professionals: https://www.youtube.com/ watch? $\mathrm{v}=$ Y9OU8f7SOXI\&feature $=$ emb $\log$ o Serious Illness Communication- for healthcare professionals: https://youtu.be/0h2rRoDG0eU; Patients' perspectives on End-of-Life Care - for healthcare professionals: https://youtu.be/Tb08t1R_QoE; Breaking bad news with patient' family members - for healthcare professionals: https://youtu.be/UCzs56S7nSA; Feeding tube decision in a dying demented patien - for healthcare professionals: https://youtu.be/3hah79LlpCg; Disagreements ove timing for advance care planning - for healthcare professionals: https://youtu.be pHCSwfEIIJo; End-of-Life Care for Dementia Patients - for healthcare professionals and public: https://www.youtube.com/watch?time_continue $=378 \& \mathrm{v}=\mathrm{Ay} 8 \mathrm{~S} Y \mathrm{~K}$ $1 \mathrm{vNk} \&$ feature $=$ emb_logo

35. CUHK Institute of Ageing. Jockey Club End-of-Life Community Care Project JCECC Capacity Building and Education Programmes on End-of-Life Care. http://www.ioa cuhk.edu.hk/end-of-life-care/resources/

36. Clegg A. Big Data Workshop. British Geriatrics Society, 25 November 2020. https:// www.bgs.org.uk/events/autumn-meeting-2020

37. Tsui E, Au SY, Wong CP, Cheung A, Lam P. Development of an automated model to predict the risk of elderly emergency medical admissions within a month following an index hospital visit: a Hong Kong experience. Health Informatics J. 2015;21(1):46-56. 